\title{
Resveratrol Improves Cardiac Functions of the Diabetic Cardiomyopathy Rats Via Modulation of AMP-Activated Protein Kinase and the Phosphorylated Glycogen Synthase Kinase-3 (3
}

\author{
HEND ASHOUR, M.D. ${ }^{\mathbf{1}}$; ASMAA M. SHAMSELDEEN, M.D. ${ }^{\mathbf{1}}$; HEBA S. SHOUKRY, M.D. ${ }^{\mathbf{1}}$; \\ LAILA A. RASHED, M.D. ${ }^{2}$; MOHAMED M. EL-SEBAIE, M.D. ${ }^{2}$; MOHAMED H. ELSAYED, M.Sc. ${ }^{3}$; \\ SHEREEN ABDELFATTAH, M.D. ${ }^{4}$; SAFINAZ SALAH-ELDIN, M.D. ${ }^{\mathbf{5}}$ and HANIA I. AMMAR, M.D. ${ }^{1}$ \\ The Departments of Physiology ${ }^{1}$, Biochemistry ${ }^{2}$, Faculty of Medicine, Cairo University, Pediatrics ${ }^{3}$, Al-Ahrar Teaching \\ Hospital, Zagazig, Histology and Anatomy ${ }^{5}$, Faculty of Medicine, Cairo University, Egypt
}

\begin{abstract}
Background: Resveratrol (RSV) has a wide range of diabetic cardioprotective effects. It is currently recognized as a dietary supplement.

Aim of Study: To investigate the impact of RSV on the molecular expression pattern of AMP-activated protein kinase (AMPK) and the glycogen synthase kinase-3 3 serine 9 (GSK$3(3 \mathrm{~S} 9)$ in diabetic cardiomyopathy.

Methods: We investigated this point using three groups of Wistar albino rats; control group, diabetic cardiomyopathy rats (DCM) and diabetics treated with RSV (DM-RSV) for 20 weeks. Echocardiography was performed at base line, and every 4 weeks. At the end of the study, Ex-vivo assessment of myocardial contractility was performed. The molecular changes in the cardiac tissues were evaluated in all groups for assessment of the silent information regulator (SIRT1), GSK-3 (3 S9 and the AMPK levels. Histological assessment was done for all cardiac tissues. Apoptosis was assessed by measuring the modulation in the $\mathrm{Bax} / \mathrm{Bcl} 2$ ratio and poly (ADP-ribose) polymerase-1 (PARP1) levels, trying to explore the RSV underlying mechanism of action.
\end{abstract}

Results: Marked deterioration in the cardiac functions was detected in the diabetic non treated group. The decreased levels of SIRT1, AMPK and GSK-3 (3 S9 that was associated with increased apoptotic markers, may be the cause of deteriorated cardiac functions. Assessment of the myocardial functions showed improvement in the diabetic RSV treated group. RSV aimed to normalize the hyperglycemic state and the disturbed molecular pattern associated with diabetes.

Conclusion: Prolonged RSV administration protects the diabetic hearts. This could be explained by the interplay between SIRT1, AMPK and the GSK-3 (3 S9 levels.

Key Words: Resveratrol - Diabetic cardiomyopathy - Sirtuins - AMPK - GSK-3(3S9

Correspondence to: Dr. Hend Ashour, E-Mail: hend.a.hassan@kasralainy.edu.eg

\section{Introduction}

RESVERATROL (RSV; 3,5,4'-trihydroxystilbene) a natural polyphenolic substance found in grapes, peanuts and berries, as well as their manufactured products, especially red wine. RSV has been reported to have a wide range of biological and pharmacological properties; it has gained great interest in preclinical and clinical studies due to its antidiabetic properties and cardioprotective effects [1]

We have recently demonstrated that pretreatment with low dose $(2.5 \mathrm{mg} / \mathrm{kg} / \mathrm{d}) \mathrm{RSV}$ for 2 weeks was effective in preventing doxorubicin induced HF [2].

Preclinical studies have documented that RSV can improve cardiac function in diabetic cardiomyopathy (DCM) either due to its antidiabetic actions [3] or due to direct antiapoptotic, antioxidant and antifibrotic actions that was recorded in our recently published research [4].

Interestingly, RSV prevented the pathological cardiac hypertrophy [5] that its action seems to be dependent on the molecular pattern disturbance of the diabetic cardiac muscle.

Resveratrol cardioprotective effects appear to be related to its ability to activate the diabetes dependent reduction of the endogenous silent information regulator sirtuin (SIRT1) activity [6] , a founding member of the redox-sensitive histone deacetylases that regulates cell apoptosis [7]. In the adult heart SIRT1 has been reported to exhibit the phenomenon of hormesis, where low to mod- 
erate expression protects against aging induced cardiac apoptosis and contractile dysfunction [8], while higher levels of SIRT1 expression promote cardiac hypertrophy and failure [9]

Glycogen synthase kinase (GSK-3(3) is a multifunctional protein that is constitutionally active in most tissues and phosphorylates a plethora of intracellular molecules. Its cardiac increased level in DCM has been shown to be associated with myocardial apoptosis [10]. It is well noted that members of the sirtuin deacetylases regulate GSK$3(3$ activity, where increased activity of SIRT2 inhibits GSK-3 (3 . In contrast, the effect of SIRT1 in modulsting GSK-3 3 is still doubtful.

Till this end, because RSV is widely accepted as a dietary supplement, we sought to investigate the resveratrol effects on the cardiac functions in the induced diabetic cardiomyopathy rat model, trying to elucidate the interrelation and changes in the expression pattern of SIRT1, GSK-3 (3S9 and the role of AMP-activated protein kinase (AMPK) levels.

\section{Patients and Methods}

\section{Animal grouping and experimental design:}

Thirty adult male Wister albino rats $(150-170 \mathrm{~g})$ were included in the study. All animals were kept in the animal care facility of the faculty of medicine Cairo University, and were provided ordinary rat chow and water ad libitum with a $12 \mathrm{hrs} \mathrm{light-dark}$ cycle. The current protocol was approved and supported by Science and Technology development Fund (STDF), Egypt, (Research support Grant No. \#12614). The study was conducted during 2018. Animals were allowed to acclimatize for 7 days prior to the start of study. Animals were randomly divided into three groups (10 rats each): (1) Normal control group, (2) Diabetic non treated (DM) and 3) diabetic treated with RSV (Sigma Aldrich, USA) at a dose of $2.5 \mathrm{mg} / \mathrm{kg} /$ day via oral gavage [11] for 20 weeks started just after diabetes confirmation (DM-RSV). Body weights were assessed every 2 weeks from the start (baseline) till the end of the study.

\section{Induction of diabetes:}

Streptozotocin (STZ, $52.5 \mathrm{mg} / \mathrm{kg} /$ intraperitoneal; Sigma, St Louis, MO). Five days after STZ injection, hyperglycemia was documented. Rats with blood glucose concentrations $>300 \mathrm{mg} / \mathrm{dl}$ were considered to be diabetic and were included in the study [12]
Assessment of cardiac function:

Echocardiography:

Echocardiography was performed at baseline, and every 4 weeks throughout the study period for recording fractional shortening (FS\%) and ejection fraction (EF\%). Two-dimensional B-mode recording of short axis view using an $8-10 \mathrm{MHz}$ liner transducer attached to an ultra-sonographic machine (Samsung Madison, SONOACE-R3-Korea).

\section{Ex-vivo cardiac contractility assessment:}

At the end of the study hearts from all groups were isolated through a midline thoracotomy under pentobarbital (150mg/kg i.p.) anesthesia [13]. Hearts were rapidly excised and immediately placed in ice cold Kreb-Henseleit heparinized solution. The ascending aorta was cannulated to attach the heart to a non-recirculating water-jacketed, constant flow Langendorff apparatus (Radnotti; Harvard Apparatus USA). Hearts were perfused with a Kreb-Henseleit buffer ( $\mathrm{pH}$ 7.4) aerated with a mixture of $95 \% \mathrm{O}_{2}-5 \% \mathrm{CO} 2$ [14]. A saline filled latex balloon connected to a pressure transducer (Ad Instruments, MLT0380, Australia) was inserted into the left ventricle through an incision in the left atrial appendage. Hearts were allowed to stabilize for $30 \mathrm{~min}$. Left ventricular pressure was recorded through Powerlab 4/30ML866 and analyzed using Labchart 7 software. The Left ventricular developed pressure (LVDP) and maximum rate of pressure rise AP/At max as an index of myocardial contractility independent on the humoral factors were recorded.

\section{Histological preparation:}

Immediately after langendorff, heart specimens were rapidly removed, fixed in $10 \%$ formal saline solution, processed, embedded to obtain paraffin blocks and cut at 5-6 micron thickness sections. Sections were stained with Haematoxylin and Eosin.

\section{Immunohistochemistry:}

Endogenous peroxidase activity of the heart specimens was blocked by 3\% hydrogen peroxide solution. The antigen retrieval was performed by heating the sections in $10 \mathrm{mM}$ sodium citrate buffer, in a water bath at $95-100^{\circ} \mathrm{C}$ for 20 minutes. Sections were rinsed in PBS for 5 minutes, and then normal goat serum was added for 30 minutes at room temperature. Then, the sections were incubated with Anti-SIRT 1 antibody (ab 110304; 1:100), AntiAMPK alpha 1 antibody (ab3759; at 1: 5000), Anti- GSK-3 (3 S9 antibody (ab15314; 1: 100) and anti-active caspase- 3 antibody (ab2302; $1: 100)$. The sections were subsequently incubated with goat 
anti-rabbit IgG H\&L (HRP) (ab205718) for $20 \mathrm{~min}$ at $37^{\circ} \mathrm{C}$. The used chromogen was DAB, and the all above-mentioned immunohistochemical sections were envisioned with 3, 3'-diaminobenzidine (Sigma, Aldrich) and observed under a microscope to see the development of color. Next to washing with distilled water, the sections were counterstained with hematoxylin, permeabilized with xylene, mounted with resin and treated with a decreasing ethanol series. All antibodies were purchased from Abcam, Cambridge, U.K. Negative control sections were performed using the same previous procedure except that the primary antibody was replaced by non-immune mouse serum immunoreactivity.

\section{Histomorphometry:}

The area percent for each marker was measured. The measurements were made by an independent viewer, who was ignorant of the experimental procedure. They were acquired in ten non overlapping fields per specimen at a magnification of 400 by using Leica LAS V3.8 image analyzer computer system (Switzerland).

\section{Blood sampling and Biochemical assays:}

Samples collected at the end of the study, were used for detection of blood glycated hemoglobin (HbAlc) using rodent HbAlc assay kit and measurement of serum lipid profile (cholesterol and triglycerides) using commercially available kits (BioMed, Cairo, Egypt).

\section{Immunoblotting detection of apoptotic marker PARPI and Bax/Bcl2:}

Immunoblotting were performed to detect PARP1, Bax and Bcl-2 protein expression in the heart tissues. Primary antibodies against PARP-1, Bax, Bcl-2 (1: 500) and b-actin (Sigma Aldrich; St. Louis, MO, USA 1: 1000), and secondary antibody (Santa Cruz Biotechnology; 1: 2000) were used according to the manufacturers protocol.

\section{Statistical analysis:}

The results were expressed as mean \pm standard deviation. Statistical analysis was done using software statistical package SPSS (IBM. Chicago, IL, 2011). The analysis of variance (ANOVA), followed by Benferoni's post hoc test were performed for multiple comparisons between groups. Results were considered significant when $p$-value was $<0.05$. Pearson correlation test was done to find out the linear relations between SIRT1, GSK-3 $\beta$ S9, AMPK and caspase-3 levels.

\section{Results}

Body weight:

All animals showed normal age matched body weight at baseline. All diabetic animals failed to show normal gain of weight irrespective of RSV administration (Table 1).

\section{Assessment of the cardiac function:}

\section{Echocardiography:}

There was no significant difference in $\mathrm{EF} \%$ or FS\% between all groups at baseline. The first decline in the echocardiographic parameters was noticed in the DM group at the 8 th week, and then $\mathrm{EF} \%$ and $\mathrm{FS} \%$ progressively deteriorated to reach (42.3 \pm 8.36 and 19.58 \pm 4.5$)$ compared to controls (84.76 \pm 5.9 and $43.57 \pm 5.6)$ respectively, at the 20 th week. Resveratrol treated diabetic rats (DM-RSV) showed significant $(p<0.05)$ amelioration of the cardiac function starting from the $16^{\text {th }}$ week of treatment (Fig. 1)

\section{Isolated heart perfusion:}

The ex-vivo cardiac function confirmed that of the Echo at the end of the study. Hearts from DM group showed significant $(p<0.05)$ reduction in the left ventricular developed pressure (LVDP) and maximum rate of pressure rise $\Delta \mathrm{P} / \Delta \mathrm{t}$ max compared to the control. Interestingly, treatment of the diabetic rats with RSV has improved $(p<0.05)$ its cardiac contractility measurements compared to that of the diabetic group, details are demonstrated in (Table 1).

\section{HbAl c Serum cholesterol and triglycerides} levels:

Administration of RSV to the diabetic rats showed a significant $(p<0.05)$ reduction of plasma $\mathrm{HbA} 1 \mathrm{c}$ in comparison to non-treated diabetic group. RSV significantly $(p<0.05)$ reduced the cholesterol and triglycerides levels compared to the elevated levels in the diabetic group data is shown in (Table 1).

Histological analysis of the Haematoxylin and Eosin stained heart specimens:

The longitudinal sections of the cardiac muscle fibers in the control group were striated and regularly branched with acidophilic sarcoplasm. They contain vesicular central nuclei and fibroblasts. On the other hand, the muscle fibers in the diabetic group revealed marked spacing, disordered and focally degenerated myoctes. Degenerated sarcoplasm with pyknotic nuclei and increased connective tissue are clearly detected. There was cellular 
infiltration in the form of lymphocytes and neutrophils. Moreover, Fibroblasts were clearly detected (Fig. 2). In the diabetic resveratrol treated, the cardiac muscle fibers were organized with acidophilic sarcoplasm and vesicular centrally located nucleus, but with slight focal degeneration and fibroblasts.

The transverse sections of the cardiac myocytes in the control group showed acidophilic sarcoplasm and central vesicular nucleus separated by connective tissue fibers (Fig. 3). On contrary, the myocytes in the diabetic group were degenerated with karyolitic nuclei. The sarcoplasm was vacuolated with pyknotic nuclei. Amplified amount of connective tissue, cellular infiltration and fibroblasts were obviously noticed. The diabetic resveratrol treated group exhibited well-maintained cardiac muscles with acidophilic sarcoplasm that enclosed central vesicular nucleus, vacuolated sarcoplasm and fibroblasts were seen (Fig. 3).

\section{Histomorphometric results:}

Molecular changes in cardiac tissues were evaluated in samples at the 20 th week for all groups, using the morphometric calculations to assess the underling molecular pattern. The mean area percent immunoexpression of the diabetic group showed about $45 \%$ for SIRT 1 and $41 \%$ for AMPK decrement when compared to that of the control group. Meanwhile, the mean area percent in the diabetic resveratrol treated group was significantly higher by $67 \%$ for SIRT1 and $60 \%$ for AMPK than the diabetic group (Fig. 4)
The mean area percent of GSK-3 $\beta$ S9 immunoreactivity of the diabetic and diabetic resveratrol treated groups exposed $50 \%$ and $20 \%$ significant decrease respectively when compared to that of the control group. However, the area percent in the diabetic resveratrol treated groups displayed about $61 \%$ significant increase when compared to that of the diabetic group (Fig. 5).

The mean area percent of caspase immunoreactivity of the diabetic and diabetic resveratrol treated groups were 1.2 folds and $68 \%$ significantly higher than the control group. The area percent in the diabetic resveratrol treated groups was about $23 \%$ significantly lower than the diabetic group (Fig. 5)

\section{Apoptotic marker detection:}

Analysis of the $\mathrm{Bax} / \mathrm{Bcl} 2 \mathrm{Ratio}$, the highest ratio was seen in the diabetic (DCM) $(41.7 \pm 9.9)$ group that was reduced significantly $(p<0.05)$ with resveratrol treatment (DM-RSV) $(10.7 \pm 2.3)$. Western blot of poly (ADP-ribose) polymerase-1 (PARP1) showed an elevated level in the diabetic rats $(6.85 \pm 0.45)$ compared to the control group that was reduced in the DM-RSV $(3.58 \pm 0.45)$ compared to the DM group (Fig. 6)

\section{Correlations:}

We performed correlation study between the molecular parameters to detect the association between the expression levels of SIRT1 and AMPK and GSK-3 $\beta$ S9. SIRT1 was positively correlated with AMPK ( $r=0.78)$, and with GSK-3 $\beta$ S9 $(r=0.79)$ and negatively correlated with caspase-3 $(r=-0.796)$ (Fig. 7).

Table (1): The body weight, glycated hemoglobin, lipid profile and the contractility assessment of the heart.

\begin{tabular}{|c|c|c|c|}
\hline & Control & $\mathrm{DM}$ & DM-RSV \\
\hline Body weight at the 20 th week (g) & $275.67 \pm 7.1$ & $194.8 \pm 9.5^{*}$ & $216.3 \pm 11.2 *$ \\
\hline HbA1c $(\%)$ & $4.45 \pm 0.65$ & $8.8 \pm 0.7 *$ & $6.07 \pm 0.6^{*} \#$ \\
\hline Cholesterol (mg/dl) & $92.17 \pm 6.79$ & $184.3 \pm 11.64 *$ & $125 \pm 10 * \#$ \\
\hline Triglycerides (mg/dl) & $56.67 \pm 5.2$ & $121.67 \pm 8.16^{*}$ & $95.67 \pm 5.32 * \#$ \\
\hline \multicolumn{4}{|l|}{ Langendorff contractility assessment: } \\
\hline LVDP (mmHg) & $101.17 \pm 9.9$ & $61.6 \pm 5.6^{*}$ & $74 \pm 4.6 * \#$ \\
\hline$\Delta \mathrm{P} / \Delta \mathrm{t} \max$ & $1187.5 \pm 158.98$ & $616.5 \pm 32.2 *$ & $821.8 \pm 80.05 * \#$ \\
\hline $\begin{array}{ll}\text { DM } & \text { : Diabetes mellitus. } \\
\text { RSV } & \text { : Resveratrol. } \\
\text { HbA1c } & : \text { Glycated hemoglobin. } \\
\text { LVDP } & \text { : Left ventricular developed pr }\end{array}$ & \multicolumn{3}{|c|}{$\begin{array}{l}\mathrm{P} / \mathrm{t} \text { max: Maximum rate of pres } \\
\text { *: Significant compared to control } \\
\text { \#: Significant to diabetic group. }\end{array}$} \\
\hline
\end{tabular}




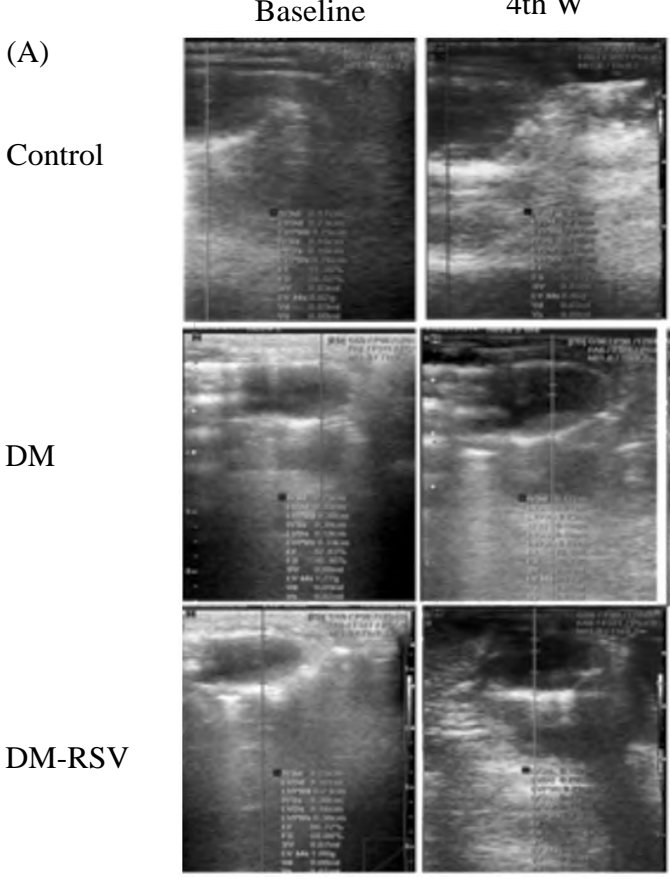

$\mathrm{EF} \%$

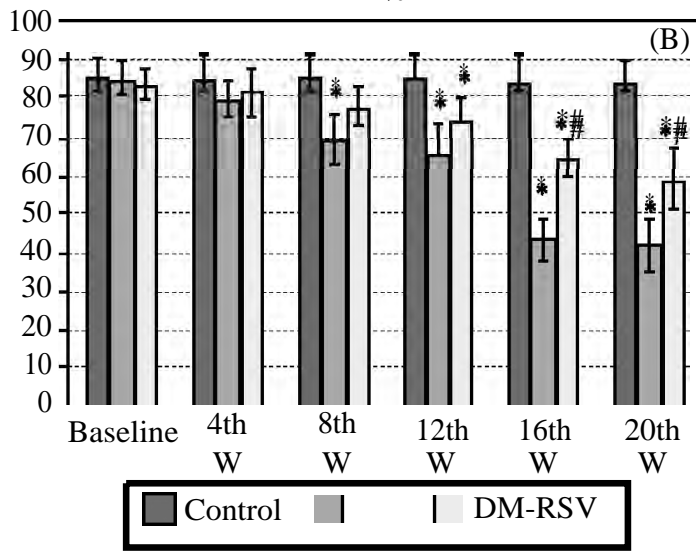

8th W
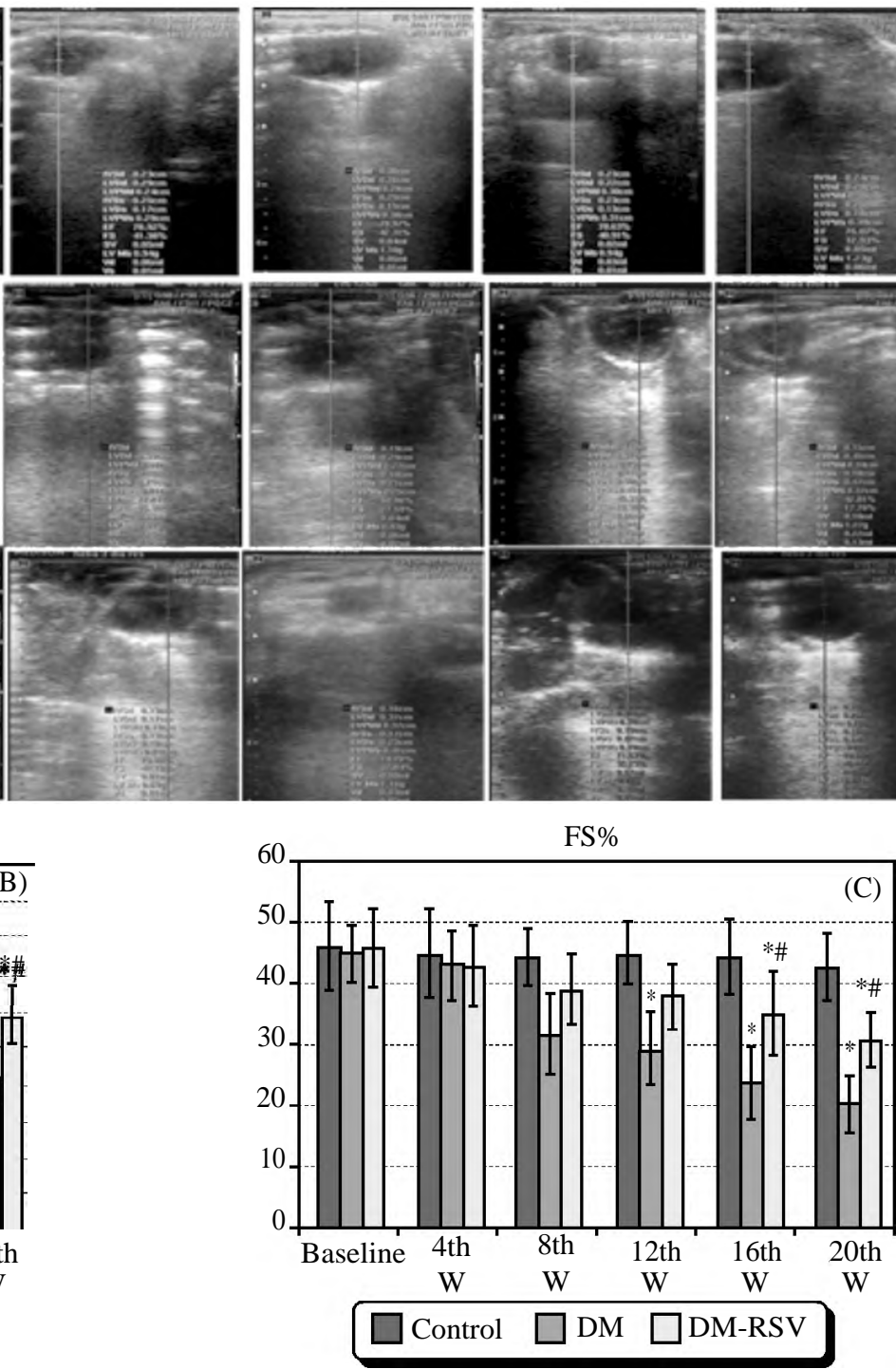

Fig. (1): Echocardiografic changes of the diabetic hearts and in resveratrol treated rats. (A) Demonstrative images at baseline and every 4 weeks till the study end. (B) Ejection fraction (\% EF) and (C) Fractional shorting (\% FS) at baseline and every four weeks during the time course of the study. Diabetic (DM) and diabetic treated group with resveratrol (DM-RSV). *: Significantly different from the respective control and \#: $p<0.05$, Significant to DM $(p<0.05)$.

Fig. (2): A photomicrograph of a longitudinal section in a rat cardiac muscle of (a) Control group, (b, c) Diabetic group displaying marked spacing between the muscle fibers ( $\mathrm{s}$ ), disrupted (D) and focally degenerated (FD) myoctes, vacuolated degenerated sarcoplasm with pyknotic like nuclei (arrow heads), increased connective tissue (CT), and cellular infiltration (CI) is also detected in the form of lymphocytes (L) and neutrophils. Fibroblasts (arrows) are clearly observed .d) diabetic resveratrol treated group showed organized cardiac muscle fibers with striations (arrows), acidophilic sarcoplasm (sp), vesicular centrally located nucleus (arrow heads). Note the presence of focal degeneration (D) and fibroblasts (thick arrows) (H\&E X400).

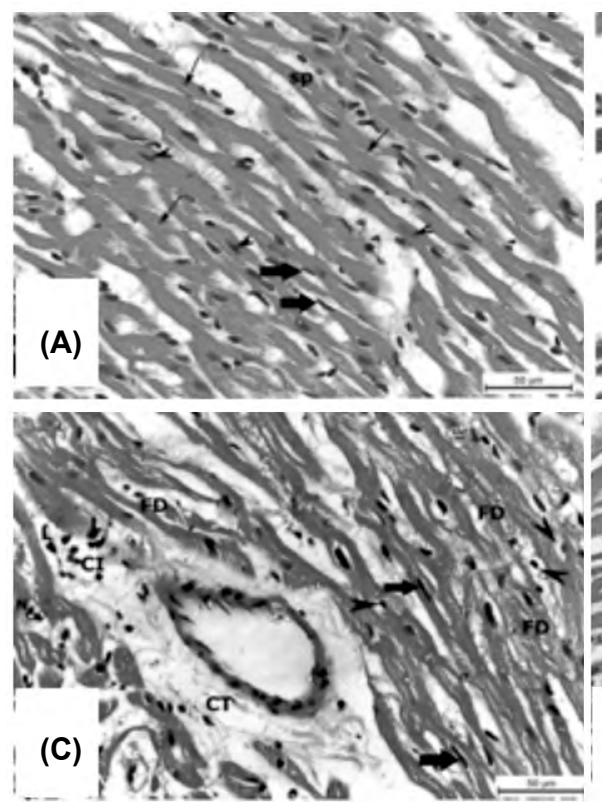




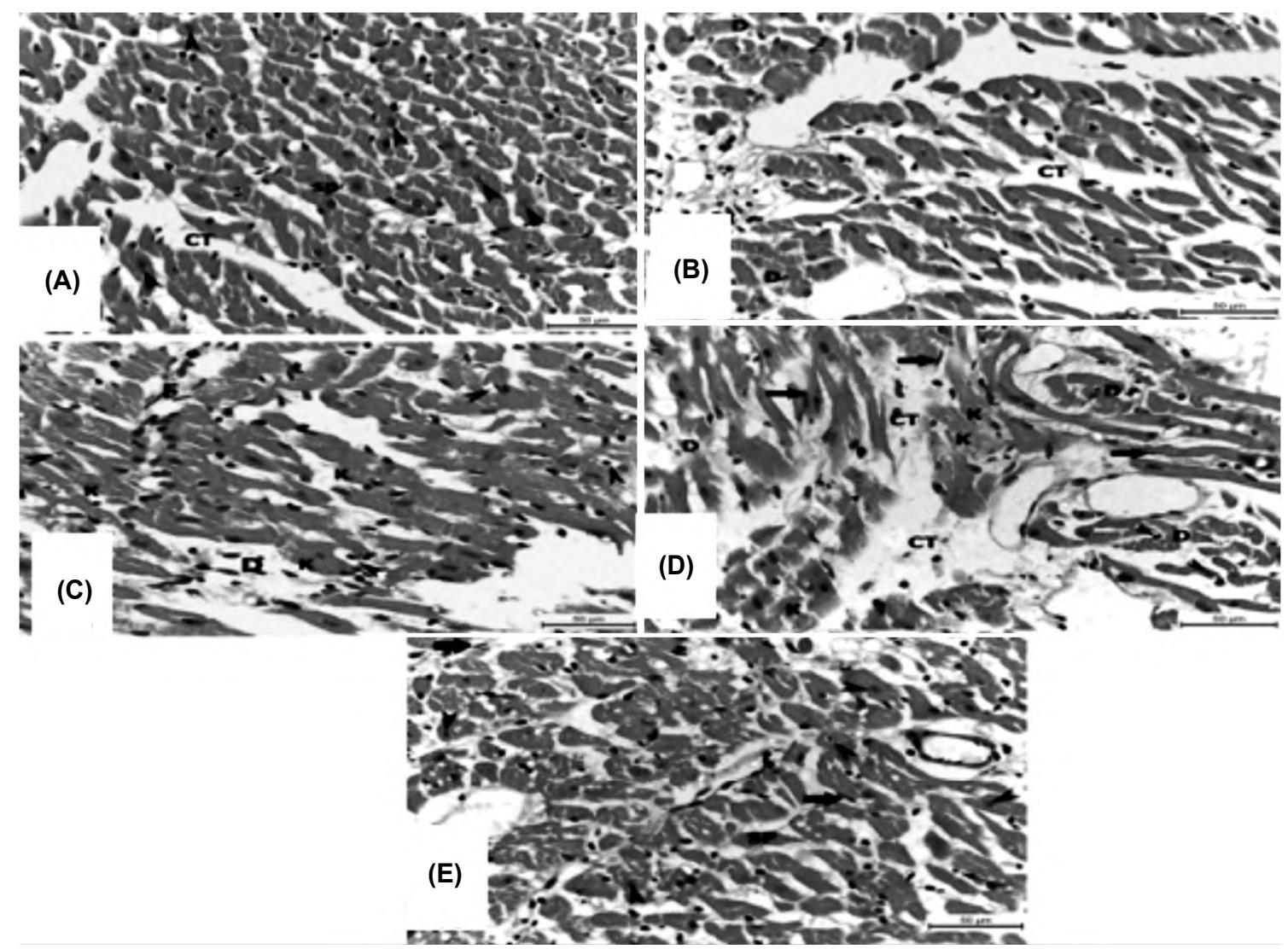

Fig. (3): A photomicrograph of a transverse section in a rat cardiac muscle of, (a) Control group. (b,c,d) Diabetic group exhibiting, degenerated (D) myoctes, degenerated cardiac muscle with karyolitic nucleus (k), vacuolated sarcoplasm with pyknotic nuclei (arrow heads), increased amount of connective tissue (CT), cellular infiltration (CI) and Fibroblasts (F) are evidently detected. (e) Diabetic resveratrol treated hearts demonstrating preserved cardiac muscles with acidophilic sarcoplasm (sp) that lodges central vesicular nucleus (arrow heads). Vacuolated sarcoplasm (thin arrows) and fibroblasts (thick arrows) are noticed (H\&E X400).
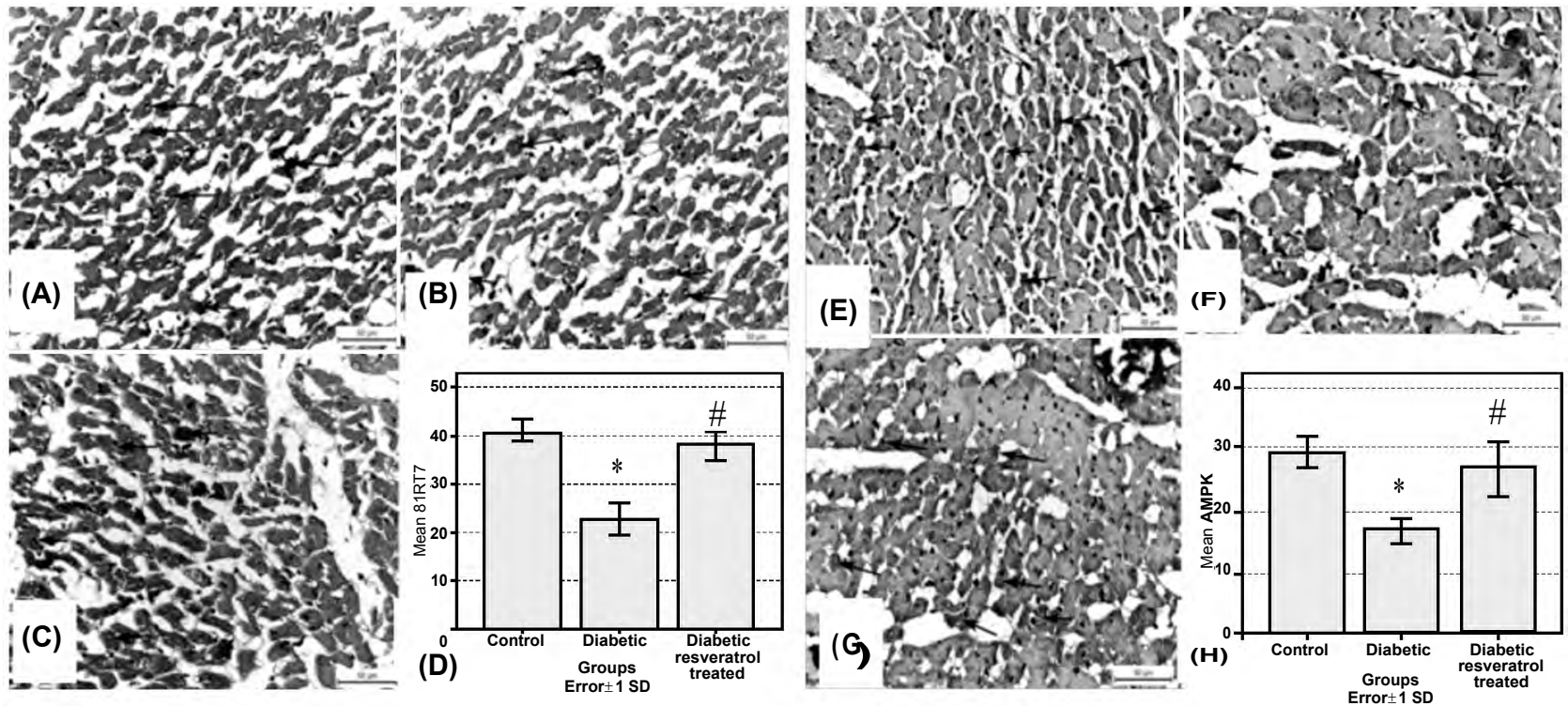

Fig. (4): A photomicrograph showing silent information regulator sirtuin 1 (SIRT1) immunoreaction in the sarcoplasm of rat cardiac muscle; (a) Control, (b) The diabetic group revealed a weak reaction. (c) The diabetic resveratrol treated shows relatively strong reaction (SIRT1 X 400) and (d) graph demonstrating the area percent of SIRT1. A photomicrograph displaying immunoreactivity in the cytoplasm of rat cardiac muscle of AMP-activated protein kinase (AMPK) in the sarcoplasm of rat cardiac muscle; e) the control groups exhibit strong reaction. (f) The diabetic group shows weak reaction. (g) The diabetic resveratrol treated shows rather strong reaction (AMPK X 400). (h) the area percent of AMPK. 

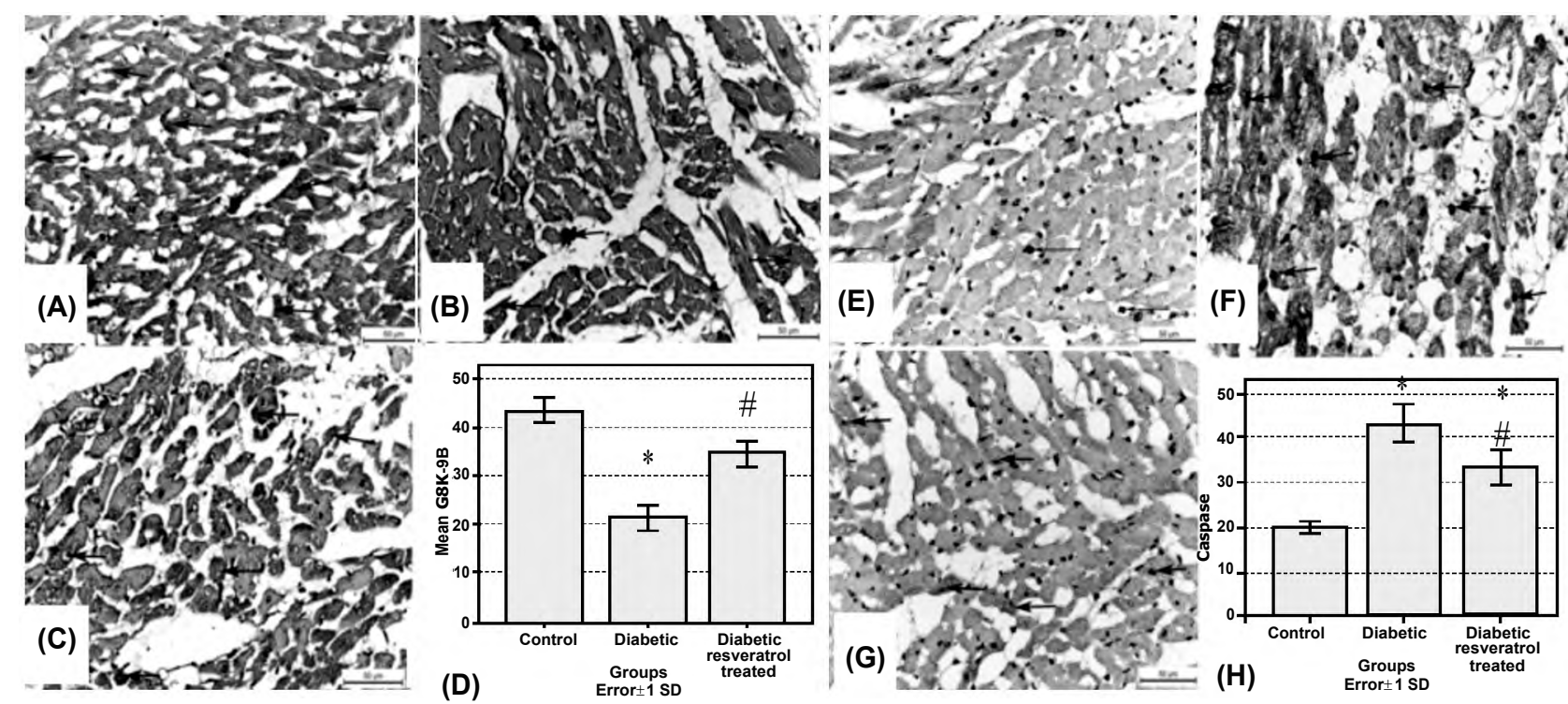

Fig. (5): The immunohisyochemical staining of glycogen synthase kinase-3 $\beta$ (GSK-3 $\beta$ ) in the sarcoplasm of rat cardiac muscle; (a) the control group shows strong reaction. (b) The diabetic group exposes weak reaction. (c) The diabetic resveratrol treated shows fairly strong reaction (GSK-3 $\beta$ X 400) and (d) The area percent of GSK-3B. *: Significant to control, \#: Significant to diabetic group. Resveratrol treated vs control $p<0.001$, diabetic vs control $p<0.001$, diabetic resveratrol treated vs control $p=0.4$, diabetic resveratrol treated vs diabetic $p<0.001$ significant). Caspase 3 immune-expression; $\mathrm{e}, \mathrm{g}$ ) the control and diabetic resveratrol treated groups indicate weak reaction. (f) The diabetic groups display strong reaction. (Caspase 3 X 400) and (h) The area percent of caspase-3. *: Significant to control, \#: Significant to diabetic group (diabetic vs control $p<0.001$, diabetic resveratrol treated vs control $p=1.00$, diabetic resveratrol treated vs diabetic $p=0.001$ ).

(A)

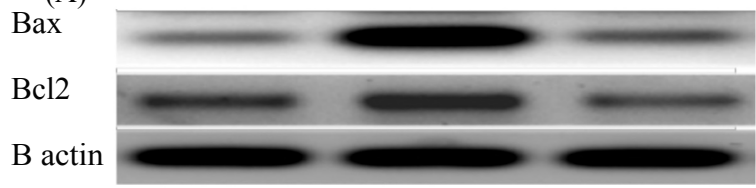

$\mathrm{Bax} / \mathrm{Bcl} 2$

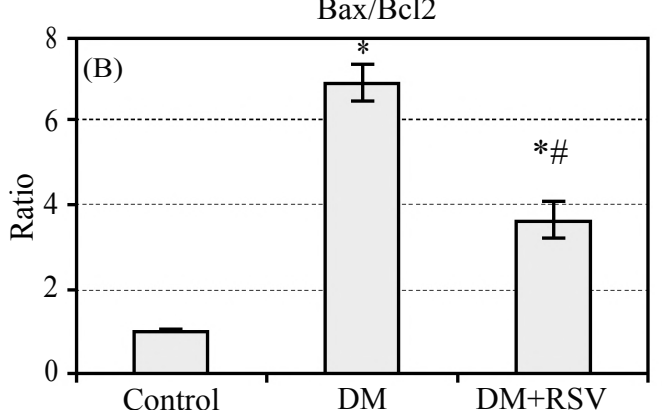

(C)

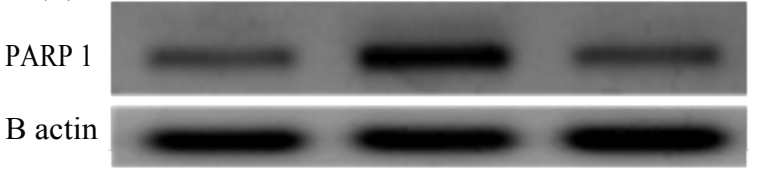

PARP 1

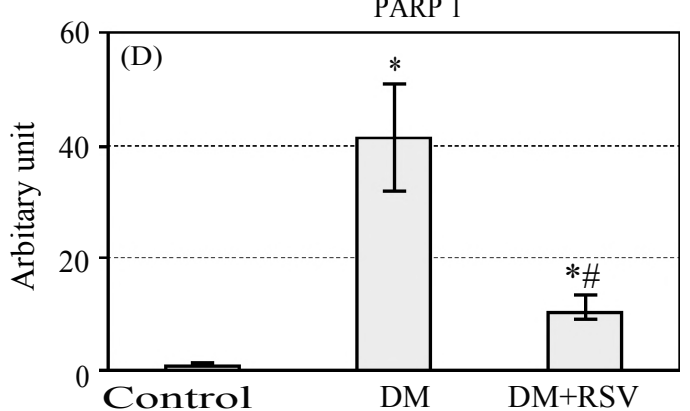

Fig. (6): Apoptotic marker changes in the studied groups A: western blot images of Bcl-2-associated X protein (Bax), B-cell lymphoma 2 (Bcl2), B: Representation of Bax/Bc12 ratio and C: Poly (ADP-ribose) polymerase-1 (PARP1). *: Significantly different from the respective control, and \#: Significant to diabetes group (DM) $p<0.05$. RSV: Resveratrol.

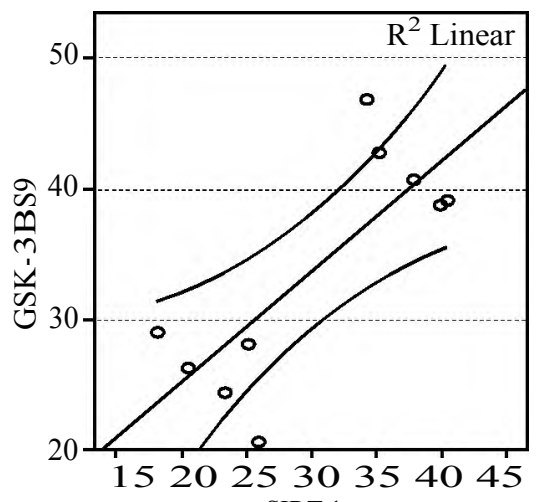

SIRT 1

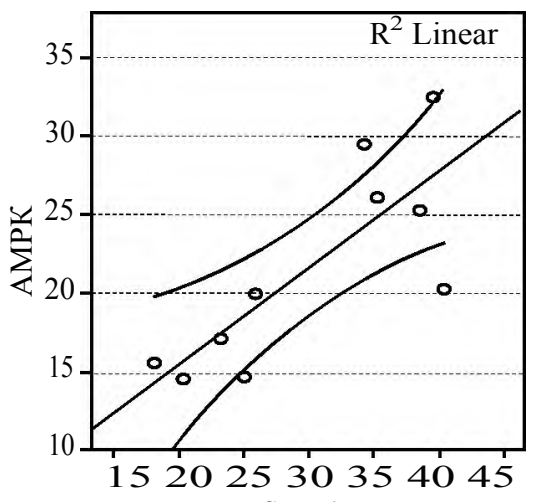

SIRT1

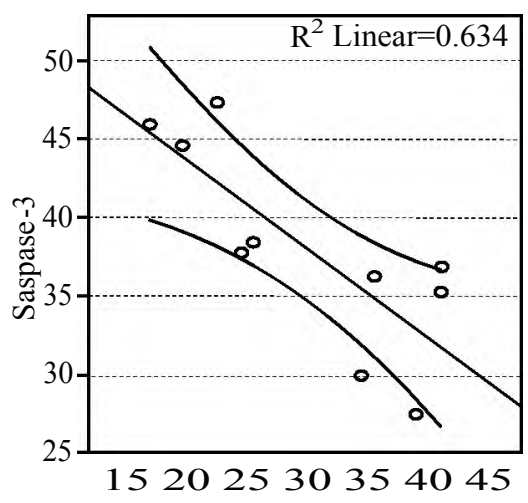

SIRT 1

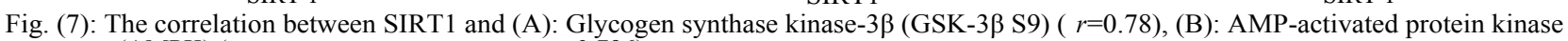
(AMPK) $(r=0.79)$ and $(C)$ : Caspase3 $(r=0.796)$. 


\section{Discussion}

In this study, cardiac functions represented by echocardiographic and Langendorff measurements were deteriorated in the diabetic non-treated group. Resveratrol treated diabetic rats for 20 weeks, protected the hearts from possible deterioration.

The pathological cellular and molecular mechanisms underlying diabetes-induced cardiac damage are complicated and multifactorial; in our diabetic model we reported cardiac molecular changes in the form of decreased SIRT1, AMPK and the phosphorylated glycogen synthase kinase-3 (GSK-3 $\beta$ S9) that was associated with the myocardial functional deterioration and apoptosis.

GSK-3 $\beta$ is considered to be the hard worker kinase in the cardiac muscle; it has a pivotal role in multiple signaling pathways acting via posttranslational modifications of its substrates [15] Hence GSK- $3 \beta$ promotes the hypertrophic responses in the heart, [16], previous reviews have detailed potential therapeutic applications of GSK3 inhibitors in cardiovascular diseases $[\mathbf{1 5 , 1 7 ]}$. Inhibitory serine-phosphorylation is the most effective mechanism that regulates GSK3 $\beta$ activity. Phosphorylation of serine-9 in GSK3 $\beta$ causes the N-terminal tail of GSK-3 $\beta$ to act as pseudosubstrate [16]. This phosphorylated serine tail hinders the binding of GSK-3 $\beta$ to its substrates, and thus diminishing its activity.

Elevated levels of GSK-3 $\beta$ S9 has been linked to improved cardiac autonomic dysfunction, reduced mitochondrial injury, improved cardiac survival, structure and function [18]. In the diabetic cardiomyopathy, the expression of post-insulin receptor signaling was extremely reduced. Subsequently, reduced the Akt phosphorylation of GSK$3 \beta$ that contributs to apoptosis and cardiac dysfunction [19].

The AMPK is a heterotrimeric enzyme acts as an important cellular energy sensor of the cardiac muscle. Conditions leading to energy depletion, such as the failing heart or increased ATP demand, also lead to AMPK activation [20]. AMPK responds to increased AMP/ATP ratio by switching off the energy-consumption and enhances the ATP generation through fatty acid $\beta$-oxidation and glycolysis. AMPK activity is also modulated by SIRT1, which is involved in the regulation of both inflammatory processes and metabolic homeostasis in the heart [21].

Resveratrol was shown to have a beneficial cardioprotection from possible diabetic cardiomy- opathy. Previous studies demonstrating cardiac beneficial effects for RSV. The treatment with RSV in a dose of $(2.5 \mathrm{mg} / \mathrm{kg} /$ day $)$ for 2 weeks [11], 4 weeks [22] and 12 weeks could improve cardiac functions in diabetic rats [23]. Furthermore, A 16 weeks resveratrol $(5 \mathrm{mg} / \mathrm{kg} /$ day; orally) treatment improved left ventricular developed pressure and reduced cardiac apoptosis in diabetic rats [24]

RSV cardio-protective effect can be related to the induced cardiac expression of SIRT1 [25]

The SIRT 1 activator SRT 1720 increased AMPK activity, whereas SIRT1-specific inhibitors decreased AMPK activity in adipocytes [26]. The effect of resveratrol may be mediated by enhanced expression of phosphorylated Akt [27] resulted in increasing the Akt downstream signaling molecule GSK-3 $\beta$ and AMPK phosphorylation [28]. Moreover, AMPK Activation could increases the phosphorylation of GSK-3 $\beta$ [29]

SIRT1 induced by resveratrol has an important role in the cell survival process. It binds and inhibits the tumor suppressor p53 and blocks the apoptotic process induced by DNA damage and oxidative stress [7]. Moreover, SIRT1 deacetylates and activates the FOXOs that in turn induce pro-survival factors like thioredoxin- 1 and $\mathrm{Bcl}-\mathrm{xL}$ and suppressing the activity of pro-apoptotic molecules like Bax and cleaved caspase 3 [30].

Resveratrol acts as a potent antioxidant factor. SIRT1 induced by resveratrol deacetylates the nuclear factor (NFkB-p65) and reduces NADPH oxidase transcription that attenuates the diabetic cardiac hypertrophy. In the same context, resveratrol guards against high glucose-induced cardiomyocytes injury through suppression of NADPH oxidase and the maintenance of endogenous antioxidant defenses [31].

Interestingly, SIRT1 deacetylates and inactivates poly(ADP-ribose) polymerase-1 (PARP1). PARP1 is a NAD-dependent enzyme that is induced by DNA strand breaks during cell stress causing ATP depletion. PARP1 would contribute to a specific type of cell death called (parthanatos) in the failing hearts [32]. Thus, both the antioxidative and antiapoptotic functions of resveratrol depended on the SIRT1 normalization [32].

Furthermore, RSV administration in this study improved the diabetic induced lipid profile and $\mathrm{HbA} 1 \mathrm{c}$ disturbances. SIRT1 was demonstrated to improve insulin resistance, decrease cholesterol along with a reduction in adipose tissue volume and total energy expenditure [33,34]. SIRT1 displays 
improved glucose tolerance due to decreased hepatic glucose production and increased adiponectin levels, without changes in the body weight [33].

The positive correlations found between a SIRT1 and AMPK and that with GSK-3 $\beta$ S9 indicate the interplay between SIRT1 induced by resveratrol and these signaling molecular correction in the hearts of diabetic rats.

In conclusion: The resveratrol protective effect on the diabetic cardiomyopathy is mediated through modulation of the existing disturbed molecular pattern induced by diabetes. RSV target was to correct SIRT1, GSK3 $\beta$ S9 and AMPK to improve the diabetic myocardial functions.

\section{Acknowledgement:}

This current work is supported and funded from the Science and Technology development Fund (STDF), Egypt, (Research support Grant No. \#12614).

Declaration of interest: All authors declare no conflict.

\section{References}

1- HUNG L., CHEN J., HUANG S., LEE R. and SU M.: Cardioprotective effect of resveratrol, a natural antioxidant derived from grapes, 47: 549-55, 2017.

2- SHOUKRY H.S., AMMAR H.I., RASHED L.A., ZIKRI M.B., SHAMAA A.A., AB OU ELFADL S.G., et al.: Prophylactic supplementation of resveratrol is more effective than its therapeutic use against doxorubicin induced cardiotoxicity. PLoS One, 12: 1-13. doi:10.1371/ journal.pone.0181535, 2017.

3- SZKUDELSKI T. and SZK UDELSKA K.: Resveratrol and diabetes: From animal to human studies. Biochim Biophys Acta., 1852: 1145-54. doi:10.1016/j.bbadis.2014. $10.013,2015$.

4- SHAMSELDEEN A.M., ASHOUR H., SHOUKRY H.S., KAMAR S.S., FADEL M., AABDELBASET M., et al.: Combined treatment with systemic resveratrol and resveratrol preconditioned mesenchymal stem cells, maximizes antifibrotic action in diabetic cardiomyopathy, doi:10.1002/ jcp.27947, 2018.

5- DOLINSKY V.W., SOLTYS C.M., WANG S. and DYCK Jr.B.: Resveratrol prevents pathological but not physiological cardiac hypertrophy, doi:10.1007/s00109-0141220-8, 2014.

6- BAGUL P.K., DEEPTHI N., SULTANA R. and BANERJEE S.K.: Resveratrol ameliorates cardiac oxidative stress in diabetes through deacetylation of NFkB-p65 and histone 3. Vol. 26. Elsevier B.V., doi:10.1016/j.jnutbio.2015. 06.006, 2015.

7- SUNDARESAN N.R., PILLAI V.B. and GUPTA M.P.: Emerging roles of SIRT1 deacetylase in regulating cardiomyocyte survival and hypertrophy. J. Mol. Cell. Cardiol., 51:614-8, doi:10.1016/j.yjmcc.2011.01.008. Emerging, 2012.
8- HSU Y.J., HSU S.C., HSU C.P., CHEN Y.H., CHANG Y.L., SADOSHIMA J., et al.: Sirtuin 1 protects the aging heart from contractile dysfunction mediated through the inhibition of endoplasmic reticulum stress-mediated apoptosis in cardiac-specific Sirtuin 1 knockout mouse model. Int. J. Cardiol., 228: 543-52, doi:10.1016/j.ijcard. 2016.11.247, 2017.

9- LI L., ZHAO L., YI-MING W., YU Y.S., XIA C.Y., DUAN J.L., et al.: Sirt1 hyperexpression in SHR heart related to left ventricular hypertrophy. Can. J. Physiol. Pharmacol., 87: 56-62, doi:y08-099 [pii] \r10.1139/y08-099, 2009.

10 - GURUSAMY N., WATANABE K., MA M., PRAKASH P., HIRABAYASHI K., ZHANG S., et al.: Glycogen synthase kinase $3 \beta$ together with $14-3-3$ protein regulates diabetic cardiomyopathy: Effect of losartan and tempol. FEBS Lett, 580: 1932-40. doi:10.1016/j.febslet.2006. 02.056, 2006.

1 1- THIRUNAVUKKARASU M., PENUMATHSA S.V., KONERU S. and JUHASZ B.: Resveratrol Alleviates Cardiac Dysfunction in Streptozotocin- Induced Diabetes: Role of Nitric Oxide, Thioredoxin and Heme Oxygenase. Angiogenesis, 43 : 720-9. doi:10.1016/j.freeradbiomed. 2007.05.004.Resveratrol., 2008.

12- MOHAN, G.N.J and N. RT.: Antidiabetic and antioxidant properties of triticum aestivum in streptozotocin-induced diabetic rats. Adv. Pharmacol. Sci., 2013.

13- DEARAUJO J.C.R., CARVALHO J.J.D., SERRA H.O.: Influence of duodenogastric reflux in the gastric mucosa histological changes of rats infected with Helicobacter pylori. Rev. Col. Bras. Cir., 43: 235-42. doi:10.1590/010069912016004003, 2016.

14- TAVARES F.M., DA SILVA I.B., GOMES D.A. and BARRETO-CHAVES M.L.M.: Angiotensin II type 2 receptor (AT2R) is associated with increased tolerance of the hyperthyroid heart to ischemia-reperfusion. Cardiovasc. Drugs. Ther., 27: 393-402. doi:10.1007/s10557013-6473-x, 2013.

15- BEUREL E., GRIECO S.F. and JOPE R.S.: Glycogen synthase kinase-3 (GSK3): Regulation, actions, and diseases. Vol. 0, doi:10.1016/j.pharmthera. 2014.11.016. Glycogen, 2015.

16- SUGDEN P.H., FULLER S.J., WEISS S.C. and CLERK A.: Glycogen synthase kinase 3 (GSK3) in the heart: A point of integration in hypertrophic signalling and a therapeutic target? A critical analysis. Br. J. Pharmacol., 153: 137-53, doi:10.1038/sj.bjp.0707659, 2008.

17- CHENG H., WOODGETT J., MAAMARI1 M. and FORCE T.: Targeting GSK-3 family members in the heart: A very sharp double-edged sword. J. Mol. Cell. Cardiol., 51: 607-1 3. doi :10.1016/j .yjmcc.2010. 11.020. Targeting, 2011.

18-ZHANG Y., WELZIG C.M., PICARD K.L., DU C., WANG B., PAN J.Q., et al.: Glycogen Synthase Kinase-3b Inhibition Ameliorates Cardiac Parasympathetic Dysfunction in Type 1 Diabetic Akita Mice. Diabetes, 63: 2097-113. doi:10.2337/db12-1459, 2014.

19- ZHANG Y., BABCOCK S.A., HU N., MARIS J.R., WANG H. and REN J.: Mitochondrial aldehyde dehydrogenase (ALDH2) protects against streptozotocin-induced diabetic cardiomyopathy: Role of GSK3beta and mito- 
chondrial function. BMC. Med., 10: 40. doi:10.1186/17417015-10-40, 2012.

20- RUDERMAN N.B., JULIA XU X., NELSON L., CACICEDO J.M., SAHA A.K., LAN F., et al.: AMPK and SIRT1: A long-standing partnership? AJP. Endocrinol. Metab., 298: E751-60, doi:10.1152/ajpendo. 00745.2009, 2010.

21- PALOMER X., SALVADÓ L., BARROSO E. and VÁZQUEZ-CARRERA M.: An overview of the crosstalk between in fl ammatory processes and metabolic dysregulation during diabetic cardiomyopathy. Int. J. Cardiol., doi:10.1016/j.ijcard.2013.07.150, 2013.

22- TURAN B., TUNCAY E. and VASSORT G.: Resveratrol and diabetic cardiac function: Focus on recent in vitro and in vivo studies. J. Bioenerg. Biomembr., 44: 281-96. doi:10.1007/s 10863-012-9429-0, 2012.

23- WANG B., YANG Q., SUN Y.Y., XING Y.F., WANG Y. BIN, LU X.T., et al.: Resveratrol-enhanced autophagic flux ameliorates myocardial oxidative stress injury in diabetic mice. J. Cell. Mol. Med., 18: 1599-611. doi:10. 1111/jcmm.12312, 2014.

24- MOHAMMADSHAHI M., HAIDARI F., SOUFI F.G.: Chronic resveratrol administration improves diabetic cardiomyopathy in part by reducing oxidative stress. Cardiol. J., 21: 39-46, doi:10.5603/CJ.a2013.0051, 2014.

25- MENG Z., JING H., GAN L., LI H. and LUO B.: Resveratrol attenuated estrogen-deficient-induced cardiac dysfunction: Role of AMPK, SIRT1, and mitochondrial function. Am. J. Transl. Res., 8: 2641-9, 2016.

26- GU X., WANG Z., YE Z., LEI J., LI L. and SU D.: Resveratrol, an activator of SIRT1, upregulates AMPK and improves cardiac function in heart failure. Genet. Mol., 2014

27- LIN C.H., LIN C.C., TING W.J., PAI P.Y., KUO C.H., HO T.J., et al.: Resveratrol enhanced FOXO3 phosphorylation via synergetic activation of SIRT1 and PI3K/Akt signaling to improve the effects of exercise in elderly rat hearts. Age (Dordr), 36: 9705. doi:10.1007/s11357-0149705-5, 2014

28- GUO S., YAO Q., KE Z., CHEN H., WU J. and LIU C.: Resveratrol attenuates high glucose-induced oxidative stress and cardiomyocyte apoptosis through AMPK. Mol. Cell. Endocrinol., 412: 85-94, doi:10.1016/j.mce. 2015. $05.034,2015$

29- HORIKE N., SAKODA H., KUSHIYAMA A., ONO H., FUJISHIRO M., KAMATA H., et al.: AMP-activated protein kinase activation increases phosphorylation of glycogen synthase kinase $3 / 3$ and thereby reduces cAMPresponsive element transcriptional activity and phosphoenolpyruvate carboxykinase $\mathrm{C}$ gene expression in the liver. J. Biol. Chem., 283: 33902-10. doi:10.1074/jbc.M802 537200, 2008.

30- TREVIÑO-SALDAÑA N. and GARCÍA-RIVAS G.: Regulation of Sirtuin-Mediated Protein Deacetylation by Cardioprotective Phytochemicals. Oxid. Med. Cell. Longev., 1-16, doi:10.1155/2017/1750306, 2017.

31- GUO S., YAO Q., KE Z., CHEN H., WU J. and LIU C.: Resveratrol attenuates high glucose-induced oxidative stress and cardiomyocyte apoptosis through AMPK. Mol Cell. Endocrinol., 412: 85-94. doi:10.1016/j.mce.2015. 05.034, 2015.

32- TANNO M., KUNO A., YANO T., MIURA T., HISAHARA S., ISHIKAWA S., et al.: Induction of manganese superoxide dismutase by nuclear translocation and activation of SIRT1 promotes cell survival in chronic heart failure. J. Biol. Chem., 285: 8375-82. doi:10.1074/jbc. M109.090266, 2010

33- BANKS A.S., KON N., KNIGHT C., MATSUMOTO M., GUTIÉRREZ-JUÁREZ R., ROSSETTI L., et al.: SirT1 Gain of Function Increases Energy Efficiency and Prevents Diabetes in Mice. Cell. Metab., 8: 333-41. doi:10.1016/ j.cmet.2008.08.014, 2008 .

34- XIE H., HAN H-P., CHEN Z. and HE J-P.: A study on the effect of resveratrol on lipid metabolism in hyperlipidemic mice. Afr. J. Tradit. Complement, 11: 209-12, 2014. 


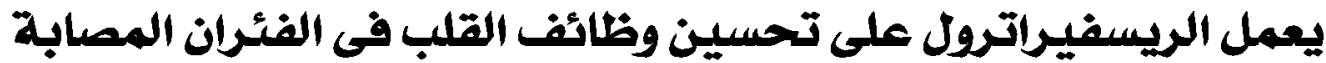

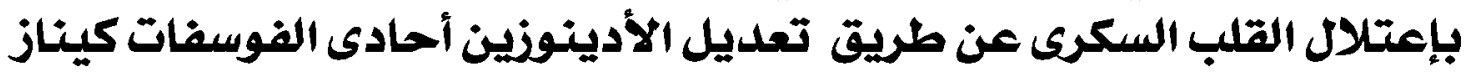 ومصنح الجليكوجين كئيناز}

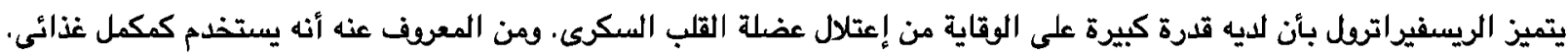

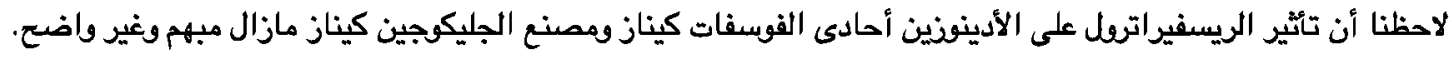
فلهذا السبب قمنا بإجراء هذه الدراسة البحث فى هذه الجزئية بإستخدام ثلاثقن من ذكود الجرذان البيضاء من فصيلة وستر. تم تقسيم

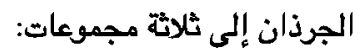

1- المجموعة الضيابطة Y- المجموعة المصابة بإعتلال القلب السكرىى. ب- المجموعة الثالثة المصابة بإعتلال القلب السكرى والتى تم علاجها بالريسفيراترول لمدة ـأسبوع.

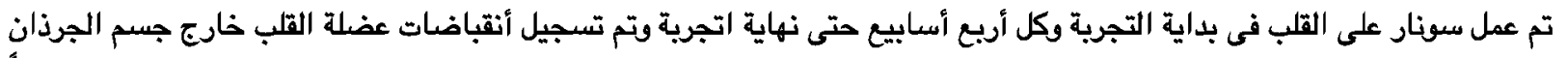

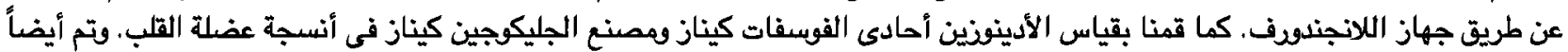
الكثف عن أنزيم بوليى رييوزيوليميريز-1 وكذلك تقييم مستوى دلالات الموت المبرمج لذايلايا القلب بغرض البحث عن طريقة عمل عقار الريسفيراترول.

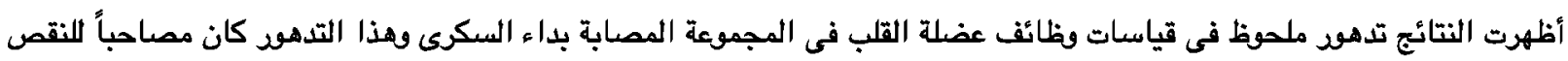

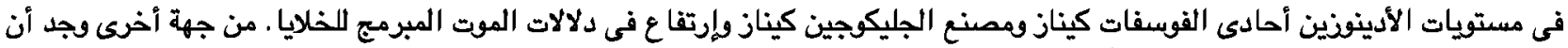

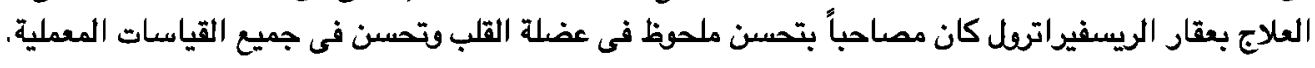
نستخلص من هذه الدراسة إن إستخدام الريسفيراترول لفترات طويلة أسفرت عن تحسن كبير فى أداء عضلة القلب في مرض إعتالكال القلب السكرى، وذلك عن طريق محاولة إعادة مستويات الإنزيمات إلى معدلاتها الطبيعية. 